\title{
Investigación y cambio social: desafíos para las ONG en Centroamérica y México
}

\section{Anthony Bebbington (editor)}

¿Cuáles son los roles reales y posibles de la investigación en la construcción de procesos de desarrollo más sostenibles, incluyentes yjustos? ¿Los centros privados de investigación tienen ventajas comparativas en este desafío? ¿Una reflexión analítica sobre el papel de estos centros ayuda a entender la relación entre sociedad civil y desarrollo, y las relaciones entre ONG, Estado y movimientos sociales? Este libro recoge parte de los resultados de un programa de reflexión, aprendizaje y autocrítica que durante dos años tuvo en las interrogantes anteriores a sus preguntas centrales.

El programa involucró a siete centros privados que, en diverso grado, priorizan la generación de conocimiento en su trabajo sobre medio ambiente y desarrollo en Centroamérica y México. El programa fue coordinado por

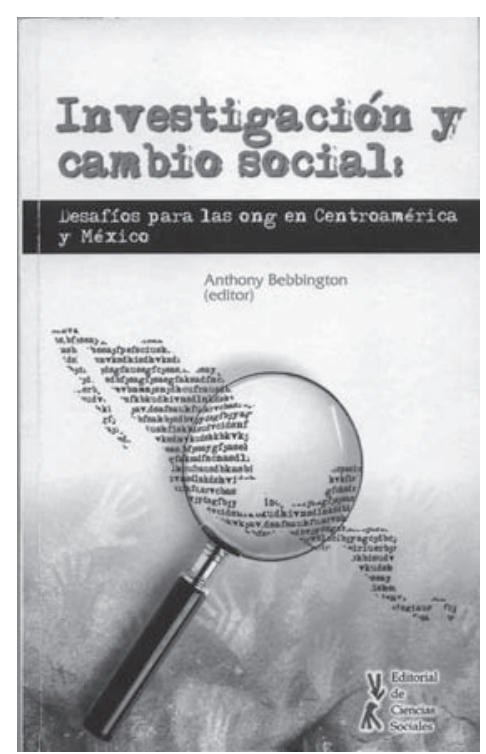
Anthony Bebbington, de la Escuela de Medio Ambiente y Desarrollo de la Universidad de Manchester y participaron los siguientes centros y personas: el Programa Salvadoreño de Investigación sobre Desarrollo y Medio Ambiente, PRISMA (Nelson Cuellar e Ileana Gómez), Nitlapán, Nicaragua (José Luis Rocha), la Facultad Latinoamericana de Ciencias Sociales-Guatemala, FLACSO-Guatemala (Iliana Monterroso), la Red de Desarrollo Sostenible-Honduras (Pedro Torres), el Grupo de Estudios Ambientales, México (Joaliné Pardo) y el departamento de PROTÓPICO del Universidad Autónoma de Yucatán (Nidia Tec, Cynthia Bazán y Adrián López). Durante el primer año también participó el Consejo Civil Mexicano para la Silvicultura Sostenible (Gabriela de la Mora).

Este programa tuvo como objetivo profundizar la reflexión, tanto en estos centros como en la Universidad de Manchester, sobre los roles que juega la generación de conocimiento en procesos de cambio social, el aporte específico de los centros privados a estos procesos y los factores de índole institucional y/o político económicos que facilitan o dificultan el cumplimiento de dichos roles. En el análisis de cada centro, el programa enfatizó la relación entre conocimientos e incidencia política y las diversas estrategias que estos centros usan o podrían usar para incidir políticamente.

* Texto de la contraportada 